\title{
FIGHT LIKE A GIRL: DIGITAL STORYTELLING FOR RESILIENCE STRATEGIES
}

By Natasha Ramoutar

\author{
An Major Research Paper (MRP) presented to Ryerson University \\ in partial fulfillment of the requirements for the degree of \\ Master in the Program of Professional Communication
}

Toronto, Ontario, Canada, 2018

(C) Natasha Ramoutar 2018 


\section{AUTHOR'S DECLARATION FOR ELECTRONIC SUBMISSION OF A MAJOR RESEARCH PAPER}

I hereby declare that I am the sole author of this Major Research Paper and the accompanying Research Poster. This is a true copy of the MRP and the research poster, including any required final revisions, as accepted by my examiners.

I authorize Ryerson University to lend this major research paper and/or poster to other institutions or individuals for the purpose of scholarly research.

I further authorize Ryerson University to reproduce this MRP and/or poster by photocopying or by other means, in total or in part, at the request of other institutions or individuals for the purpose of scholarly research.

I understand that my MRP and/or my MRP research poster may be made electronically available to the public. 


\section{Abstract}

My major research paper (MRP) seeks to explore the relationship between resilience strategies and women in martial arts. It is the foundation for a knowledge translation project which seeks to create an interactive fiction piece to teach self-motivation strategies utilized by women athletes in combat arts. This interactive fiction piece is not meant to be a clinical tool for depression or anxiety, but is instead a self-empowerment tool. By interviewing 10 women who participate in Muay Thai as amateur fighters, I was able to evaluate which strategies were common and effective. These included discipline, organization, growth mindset, and finding an overarching purpose. There were also many barriers that were similar between the participants of my study, including ineffective coaching techniques, unsupportive friends and family, and unrealistic representations of women in martial arts by the media. Lastly, the participants of my study offered several suggestions for the game creation, including designing accurate physical representations of women's bodies, acknowledging barriers and sacrifices for women in the sport, and offering the opportunity in-game for self-reflection to mimic self-improvement.

The term knowledge translation reveals that we speak in different languages and conventions than people outside of academia. The term knowledge mobilization illustrates that we have to go out of our way to reach these people, many of whom are the subjects of our research. These two concepts can and should be integrated as we conduct our research, write our papers, and publish; they should not simply exist as an afterthought. I urge every scholar who reads this paper to consider the ways we can create a culture which encourages inclusivity and equitable access. 


\section{Table of Contents}

$\begin{array}{ll}\text { Table of Contents } & 3\end{array}$

$\begin{array}{lr}\text { Acknowledgements } & 5\end{array}$

$\begin{array}{lr}\text { Preface } & 6\end{array}$

$\begin{array}{lr}\text { Fight Like a Girl - Twine Game } & 8\end{array}$

$\begin{array}{lr}\text { Introduction } & 9\end{array}$

$\begin{array}{ll}\text { Research Questions } & 11\end{array}$

$\begin{array}{ll}\text { Literature Review } & 13\end{array}$

Muay Thai $\quad 14$

Historical Origins of Muay Thai $\quad 15$

$\begin{array}{ll}\text { The Influence of Mixed Martial Arts } & 17\end{array}$

The Concept of Jai Dee or Heart 19

$\begin{array}{ll}\text { Motivation } & 21\end{array}$

Barriers for Women $\quad 22$

Tools for Success for Women $\quad 23$

Resilience \& Growth Mindset $\quad 24$

Concept of Flow $\quad 25$

Electronic \& Traditional Literature 26

$\begin{array}{ll}\text { Hypertext Fiction Strategies } & 27\end{array}$

Traditional Fiction Strategies $\quad 28$

Considerations for Twine Game 29

Content 29

$\begin{array}{ll}\text { Structure } & 30\end{array}$

Data Collection Approach $\quad 33$

Ethnography \& Autoethnography: An Extension of Biography \& Autobiography 33

Semi-Structured Interviews: A Journalism Staple 35

$\begin{array}{ll}\text { Method of Analysis } & 37\end{array}$

$\begin{array}{ll}\text { Autoethnography } & 37\end{array}$

Thematic Grouping $\quad 38$

$\begin{array}{ll}\text { Findings } & \mathbf{4 0}\end{array}$

$\begin{array}{ll}\text { External Communication } & 40\end{array}$

$\begin{array}{ll}\text { Barriers } & 41\end{array}$ 
Coaching Tools

Representation and Appearance

Representation in Muay Thai and Combat Arts

Results of Oversexualization of Women

Internal Communication

Discipline \& Organization

Resilience \& Growth Mindset

Purpose

Motivational Communication Practices

Considerations for Game Creations

Audio-Visual Considerations

Storyline Considerations

\section{Discussion}

External Communication

Internal Communication

Game Creation 


\section{Acknowledgements}

This major research paper is dedicated to all of the Muay Thai fighters who allowed me to interview them for my study. Thank you for trusting me with your stories. You are all my heroes.

This paper is also dedicated to my classmates in the Master of Professional

Communication 2018 cohort. I never thought that I would make 20+ new best friends in a year.

Thank you for your support. I love you all so much.

I am immensely grateful to my supervisor Dr. John Shiga and my second reader Dr.

Marty Fink for your valuable feedback and support. My supervisor and second reader model the type of scholar I want to be: engaging with both academic and non-academic communities, empathetic towards others, and deeply critical.

Lastly, I give an infinite number of thank yous to Leanne Simpson. You did this program in 2015-2016 your own accessibility needs that were greater than mine. Every time I told you I couldn't do something - go to class, turn in an assignment, attend orientation - you told me I could. And I believed you. And I did it. 


\section{Preface}

This major research paper is indebted to the women in Muay Thai who allowed me to interview them as participants. In thinking about the inaccessibility of knowledge production in universities, I have made several intentional choices when writing this paper. These include, but are not limited to: less formal language; choosing to approach this study as both ethnography and autoethnogaphy; and using anecdotes from my own life as grounding points. Beyond the paper, I am creating an interactive Twine game to allow participants as well as those beyond the Muay Thai and academic communities to access this information.

To those scholars that may express disdain at my choice of ethnography, use of vernacular language, or integration of personal anecdotes, I pose the following question: Can the subjects you are studying access what you have written about them? My participants come from varied backgrounds. Some possess advanced degrees, others have never been to college or university, and some finished post-secondary education a long time ago. These are women who may not know to read a specialized bibliography or may not have time to look up a specific technical term. While I do understand that there are certain conventions to academic writing, I refuse to adhere closely to convention if it means sacrificing the ease of access to those that I have studied. I do also acknowledge that this paper is not completely accessible and does include technical terms that are not commonly used outside of academia without clear definitions. I am grateful that this major research paper will be available as an open access document upon its completion because this removes a barrier. But having a paper available for download is not enough. We must be thinking about the language and formats we use. 
The term knowledge translation reveals that we speak in different languages and conventions than people outside of academia. The term knowledge mobilization illustrates that we have to go out of our way to reach these people, many of whom are the subjects of our research. These two concepts can and should be integrated as we conduct our research, write our papers, and publish; they should not simply exist as an afterthought. I urge every scholar who reads this paper to consider the ways we can create a culture which encourages inclusivity and equitable access. 


\section{Fight Like a Girl - Twine Game}

This major research project (MRP) includes a creative component to complement the academic

paper as a knowledge translation piece. The digital fiction game made through Twine is playable on Desktop only.

When the game creation is complete, the link below will be updated:

http://philome.la/placeholder 


\section{Introduction}

On my first day of orientation for the Master of Professional program, I sat fidgeting and avoiding eye contact, trying to keep myself from fainting or throwing up on the table. When my anxiety attacks began in the summer of 2017, this is how they always started. First was the dizziness, as though the ground had begun to shake below my feet. Then came the heat that would rise from my stomach, spread throughout my body, and stain my cheeks red. Last was the onset of nausea, a constantly lurching stomach. In a room full of seasoned professionals-from paralegals to instructional designers - and multiple-degree academics, I did not feel like I belonged.

To manage this anxiety, both my doctor and my program director suggested that I connect with Ryerson University's counselling service. Aside from counselling, I had one other refuge: martial arts. Both of my communities in the Afro-Brazilian martial art of Capoeira and Muay Thai, a combat art from Thailand, offered a way to reduce this anxiety through physical exercise and spending time with close friends. When I was in the gym with feet pivoting for a kick, my toes digging into the hardwood floor or cushioned mats, I didn't think about doubting myself. As I continued with counselling at Ryerson, I was referred to Cognitive Behavioural Therapy (CBT). While going through the weeks in CBT, I was struck by how similar the strategies were to the tools I had used while training for a Muay Thai fight, such as thought journals and mindfulness. Furthermore, my friends were shocked at how quickly I bounced back from the anxiety attacks, and how committed I was to self-reflection and self-improvement. I strongly believe that my success in learning how to deal with my anxiety stems from my 
experience in martial arts. In particular, I was taught many tools by other female martial artists in Muay Thai, who faced many barriers when deciding to pursue fight careers in Muay Thai. My major research paper (MRP) seeks to further explore this relationship between resilience strategies and women in martial arts. It is the foundation for a knowledge translation project which seeks to create an interactive fiction piece to teach self-motivation strategies utilized by women athletes in combat arts. This interactive fiction piece is not meant to be a clinical tool for depression or anxiety, but is instead a self-empowerment tool. I have chosen to focus on self-motivation because it can be used as a tool to self-empower, especially for those who are historically marginalized. As scholars Dorcas Susan Butt, Diana Brecher and Carol S. Dweck discuss in their work in the field of psychology, intrapersonal communication strategies which cultivate resilience such as mindfulness or optimism are beneficial for those coming from these types of communities. In particular, Dorcas Susan Butt's research, which will be further explored in the literature review, points to many female athletes who utilize these tools in the same way as the female fighters who I trained with. In my experience as a participant of this sport, the Muay Thai gyms in the Greater Toronto Area are dominated by men. This can sometimes make it difficult for women to gain respect in these spaces, especially when phrases such as "hits like a girl" are used in demeaning ways (McNaughton, 7). Since these gyms and competitions are gendered spaces, they are rich sites to explore the process of self-motivation because women face barriers when competing in this sport. The creative component aims to disseminate these self-motivation strategies to audiences beyond the Muay Thai community.

There are two parts to this project. The first stage consists of a literature review and interviews on how women show resilience and self-motivation as amateur athletes in Muay Thai. 
The second stage is the knowledge translation project involving a game creation. This will include writing a script for the game based on my interviews to represent a "typical" woman fighter in Muay Thai, inputting this script into the Twine program to generate a playable game, and doing a quality assurance roll out with peers to ensure the game works in its technical aspects.

\section{Research Questions}

1. According to scholarly literature, what motivational strategies have been linked to the empowerment of women, particularly in the context of athletics?

This first question will be informed by the Motivation section of my literature review to explore the relationship between women in athletics and self-motivation strategies. In completing my brief survey literature, especially within sports psychology, I acknowledge that my review is limited in that it often focuses on women in various positions of privilege: cisgendered, white, able-bodied, hetereosexual, etc. Due to this, my study and literature review cannot be considered fully intersectional. The term "intersectional" was coined by Kimberle Crenshaw in her 1989 article "Demarginalizing the Intersection of Race and Sex: A Black Feminist Critique of Antidiscrimination Doctrine, Feminist Theory and Antiracist Politics" in response to how the experience of Black women were separated into "women's experience" or "the Black experience." (Crenshaw, 140). Instead, she advocated for these two experiences to be discussed in conversation to show the multiplicity of barriers Black women would experience based on two parts of their identity. While I would have liked to take an intersectional approach to both the 
literature review and findings to explore how certain women are disempowered more than other women - including trans women, women who are not lean, who have disabilities, and/or who are queer, among many other considerations - but this is beyond the scope of my MRP which is limited in length. This will be discussed more in the conclusion section as opportunities for future research.

My literature review puts different fields which are not commonly grouped together such as sports psychology, communications studies, and feminist rhetoric into conversation. It identifies several strategies in the context of athletics for women which will be used for self-empowerment.

2. Do media images, social media discourse, and communication among fighters and coaches in the Muay Thai gyms support or create barriers for women in the sport?

This question is informed by both the Muay Thai section and the Motivation section of my literature review to explore how women in the sport experience external communication. This includes but is not limited to idealized body image, positive and negative reinforcement, and familial expectation of women. I will then take the external communication forms found in the literature and evaluate whether these Muay Thai fighters continue to experience these in a way that is empowering or disempowering.

3. What are the self-motivation strategies used by women who are amateur Muay Thai fighters? 
I evaluate whether or not the techniques described in the literature review, such as positive thinking and meditation, match the strategies used by women who are amateur Muay Thai fighters that are disclosed in the interviews. This section is also informed by the Muay Thai section of the literature review because of its intersection with gender. While I draw from the list of self-motivation strategies identified in the literature, my analysis of the interviews is open to strategies that are not mentioned in the literature, especially considering that none of the literature focused on the specific context.

4. How can digital literature and storytelling be used as pedagogical tool to teach these self-motivation and resilience strategies to the general public — particularly young adults who are drawn to gamification — beyond the Muay Thai community?

a. How can digital literature and storytelling be used to represent the experiences of these women, provide insight into their unique experiences, and build empathy?

This section is connected back to the Electronic \& Traditional Literature section of my literature review. As mentioned, digital fiction is praised for providing choice to a viewer. The basis of using Twine to create the game is to use a platform which offers multiple choices, but can still retain a script that uses traditional narrative techniques. This section also engages with insights drawn from the Muay Thai section of my literature review regarding issues of representation, and guides my effort to ensure that the lived experiences of the sport are accurately depicted in the fiction created. 


\section{Literature Review}

I use an interdisciplinary approach to my literature review to draw from work on several topics in different scholarly communities. These topics include the socio-cultural, gendered, and raced space of Muay Thai; female and athlete motivation and resilience strategies; and best practices for electronic literature creation.

\section{Muay Thai}

This subsection on Muay Thai is informed by my own experience as a Muay Thai athlete, which influences my approach to the sport from both Western and Eastern viewpoints, the manner in which I found sources to confirm the oral histories of the concept of Jai Dee and the myth of Nai Khanom Tom, and the way I drew on sources which resonated with my experience as a woman training in Muay Thai. Since Muay Thai is often grouped together with sports like boxing, kickboxing, and mixed martial arts, I also explore concepts of racial norms and gender to evaluate who primarily has access and media coverage within the sport.

Although I have a background in martial arts and dance, I was afraid to try Muay Thai. I began training the Afro-Brazilian martial art of Capoeira in 2012 at Kadara Capoeira, which seemed less intimidating than other martial arts because of its dance elements, its mixture with acrobatics, and its abundance of female participants. When we moved into Studio B at Southside Muay Thai, I would often peek into Studio A at the Nak Muays (Muay Thai fighters), their sweat dripping onto the bright blue mats and the mirrors fogging up from the body heat. Although the 
instructors at the gym were very welcoming and invited me to train whenever they saw me peeking in, I had very specific preconceived notions of who could train in this combat art. I worried that Muay Thai was too violent and dangerous for me, a short, skinny 115 lbs girl. I thought that Muay Thai was a sport for men and that the gym would be overrun with egos. It took the encouragement of my capoeira instructor and capoeira teammates to convince me that I could try it. Once I did, I realized that while Muay Thai did have risks of injury, the core of it was not hyper-masculine egotism. Instead, the artform had a considerable emphasis on culture and character-building. This section of the literature review explores those same loves and fears: the history of Muay Thai, the influence of Mixed Martial Arts (MMA), and the concept of heart or Jai Dee.

\section{Historical Origins of Muay Thai}

Muay Thai or Thai kickboxing is a popular sport in Thailand which originated in the fifteenth century as a form of military combat and is considered by many as the deadliest combat art, as noted by Historian Arne Kislenko (148). Muay Thai is heavily ingrained as a historical practice. Scholar Peter Vali states that Thai government ministries and universities characterize Muay Thai based on its historical value to the royalist national history (509). Muay Thai is also closely related to Muay Boran, which "is a collection of non-sporting forms of muay purported to represent the origins of Muay Thai” (Vali, 510). Lastly, Vali claims that Muay Thai embodies “Thailand's national "warrior spirit” (512).

Coming from Thailand, the martial art is heavily influenced by Buddhist practices (Kislenko, 148). Although contested by some Western and Thai scholars, Buddhism is "seen by 
some as a kind of moral framework for male domination" which may lead to the oppression of women as a result (Kislenko, 13). The depiction of Buddhism as connected to combat art is in contrast to Western conceptions of Buddhism, including the American interest in Buddhism during the early Cold War years which gave rise to Dharma Bums and the Beat Generation. Historian Michael K. Masatsugu describes a high school teacher, Robert Jackson, who believed "the Beat lifestyle and the approach of white Buddhists embodied the true spirit of Buddhism, even when compared to those Japanese Americans that had been raised Buddhist," and lauded their pacifism and rejection of worldly goods (424). Masatsugu then criticizes this by invoking an article by Taitetsu Unno, a Nisei (second-generation) Buddhist, who believed, "the Beat Buddhists celebrated by Jackson were misguided in their spiritual pursuits and often failed to engage Buddhist teachings on anything more than a superficial level" (424). As Buddhism is an East Asian religious and cultural practice, it is important to acknowledge that those like Robert Jackson were writing outside of the culture. For my own study, it is a reminder to be mindful of the history of Buddhism and its appropriation and representation in Western texts.

One tale that is integral to understanding the origin of Muay Thai is the legend of Nai Khanom Tom. In the World Muaythai Council's recounting of the tale, they describe Nai Khanom Tom as a Thai war prisoner in Burma in 1774 who defeated ten Burmese fighters during a festival and earned his freedom (World Muaythai Council).Their description of "the fighting art of the spiritual warrior" points to the aforementioned Buddhist and warrior spirit influences (World Muaythai Council). Furthermore, the description of the legends surrounding Muay Thai as "historically based on truth" positions the artform as the historically and culturally important as previously stated (World Muaythai Council). Despite Western associations of 
Buddhism as synonymous with pacifism, the its history is far more complex and, much like Muay Thai, its meanings vary between cultural contexts.

\section{The Influence of Mixed Martial Arts}

While Muay Thai is an East Asian martial art and cultural practice from Thailand, most Western audiences come across the combat art as a component of Mixed Martial Arts. Mixed Martial Arts (MMA) has risen in popularity in recent years because of the Ultimate Fighting Championship (UFC). As described on their website, the UFC takes inspiration from "a Brazilian form of MMA known as Vale Tudo (anything goes)," combining many martial arts “including karate, jiu-jitsu, boxing, kickboxing, grappling, wrestling, sumo, and other combat sports” (UFC). Peter Vali notes that Muay Thai in Thailand is "regularly depicted as a "national" martial art that inculcates peacefulness, whose practitioners only resort to aggression when attacked" (518). Vali argues that the rise of Mixed Martial Arts (MMA) “[emphasizes] violence, hyper-masculinity, efficacy and winning in the ring over other benefits commonly attributed to martial arts practice, like character-building and philosophical introspection and bodily awareness" (532). Similarly, sociologists Akihiko Hirose and Kay-Kei-ho Pi argue that "the elements of MMA that have an external connection tend to involve hypermasculine and hyperheterosexual discourse" (198). They further complicate this idea by drawing attention to the intersection of gender and race, noting that East Asian masculinities are "often feminized, yet selectively authorized by their white American counterpart" (190). Furthermore, East Asian men are conceptualized in Western society as "weak, nerdy, feminine and asexual compared to the idealized form of white 
masculinity" but at the same time portrayed as "hypermasculine kung-fu masters" (191). While hegemonic Western white masculinity is pervasive in MMA, it is important to acknowledge this is used to disempower men who do not fit the stereotype, including men of different ethnicities from countries where these sports (such as Karate, Japanese Jiu-Jitsu, Sumo, and Muay Thai, among others) originate.

The prominence of MMA and conceptions of masculinity in combat arts affects the experience in local martial arts gyms as well, especially for women. In communication scholar Melanie Joy McNaughton's auto-ethnographic article, “Insurrectionary Womanliness: Gender and the (Boxing) Ring," she describes her experience training Muay Thai in a Western setting. As later documented in the Motivation section of my literature review, McNaughton asserts that women are often perceived by people in Western society as gentle, weaker, more cooperative, and less aggressive. As a result, women are constantly devalued in the gym where she trains. In one experience, she recounts how "[the men] habitually attempt to demean their partner by telling him he "hits like a girl"' (7). She also describes the broader implications of the gender gap in sports by stating that the connection between masculinity and elite athleticism "has meant that female participation in competitive sport has been slow to grow," noting the lack of funding and opportunities for women (3). There are many possible reasons for why Western Muay Thai gyms are often oppressive spaces for women. As discussed by Peter Vali, Akihiko Hirose, and Kay-Kei-ho Pi, part of this comes from MMA focusing on violence rather than character-building and other benefits of martial arts. Melanie Joy McNaughton argues that urbanization, industrialization, and the entrance of women into the workforce have caused men to turn to the sport as a place to express hegemonic masculinity (3). In my personal experience, 
boxing has also often been characterized in this way to emphasize violence, hyper-masculinity, and efficacy, being popularly dubbed the "gentleman's sport." For the purpose of my project, I am choosing to develop an alternative lense to the intense North American-centric and Eurocentric lenses which surround sports like MMA and boxing, and instead focus on directly on Muay Thai which falls within East Asian martial arts.

\section{The Concept of Jai Dee or Heart}

One strategy for developing alternatives to the representation of Muay Thai in popular culture is to turn to the discourse of Muay Thai participants. They prove to excellent sources of concepts for thinking about the relations between motivation, communication, and gender. One key concept of Muay Thai which expands on benefits of martial arts is the concept of Jai Dee or heart, which has significant overlap with concepts from psychology like resilience. After doing a thorough search within the Ryerson University library, I could not find a suitable source which clearly explained the concept of heart in a way that matched my personal experience participating in Muay Thai in Toronto. When a conversation is happening within the public sphere but not in the scholarly sphere, I believe it points to a gap within academia and that these gaps are related to inequities in access to academia and the consequent focus on some topics but not others. Furthermore, if the topic is a new or emergent issue, new knowledge may be delayed because of the lengthy review process for scholarly journals. For this reason, I have chosen to use popular sources and an expert interview for this section. 
The article "What It Means to Have 'Heart' in Muay Thai" by a user identified as Stephen on the website Muay Thai Pros breaks down this concept of heart. From my experience in the Muay Thai community, heart can be described as will or grit. This article was sent to me by a teammate in my early days of training when I asked her how to cultivate the motivation to come to training everyday when I felt small, weak, and disadvantaged in comparison to my teammates. The four key points of heart that Stephen describes are: "being a fierce competitor"; "refusing to lose"; "never, ever, quitting"; and "giving it your all" (Muay Thai Pros). Many of these points overlap, and all point to putting your entire effort into an activity despite encountering obstacles. Furthermore, they exemplify the aforementioned character-building qualities.

During an expert interview that I conducted with with Kru Jenypher Lanthier, a former Muay Thai champion, local Muay Thai gym owner, and head instructor at York Muay Thai, she described heart in a similar way. She stated: "you can call it will or heart, but at the end of the day someone has something inside of him that's bigger than him that he needs to get out," and pointed to Muay Thai as an outlet. She further described this concept as fire, a lion, or passion, and noted that those coming to Muay Thai with a more difficult history often were able to draw on this spirit more. She described these types of fighters as those who come from a culture that has struggled, and used the word culture to encompass experiences like being bullied or being part of a marginalized ethnic group alike. Kru Jenypher Lanthier stated that heart can be developed, but is difficult to develop if it's not something that is already in the fighter, which differs from concepts like resilience. Although it is a cultural concept, it does have some overlap with concepts of grit and growth mindset which will be explored in the motivation section. 
As demonstrated by this section of the literature review, the transnational migration of Muay Thai caused a shift in the perception of the sport. While in Thailand it is regarded as both an art form and military tactic with Buddhist influence, mixed martial arts productions like UFC are aimed at Western audiences and tend to emphasize hypermasculinity and violence. This hypermasculine view contributes to the marginalization of women in sports, most evidently through a lack of funding opportunities for women athletes which is discussed in the subsequent section, but also in subtle ways such as insulting language in the gym. The concepts and insights gathered from these scholarly texts resonate with and validate my own experiences as a female Muay Thai practitioner. These perceptions of gender and Muay Thai will be used in the game creation section of my MRP to accurately depict the hardships women face in the gym, in combination with the data gathered in my interviews.

\section{Motivation}

This subsection explores motivation, both internal and external, as well as barriers to achieving a motivated state of being for women in athletics. Once again, this section is informed by my personal experience. While I did not encounter a violent, hypermasculine environment in the gym when I began Muay Thai, that does not mean there were not barriers for me and other female athletes. The fact that I did not think I could try the martial art to begin with is indicative of the number of self-imposed and/or structural barriers. Once I began training, I often held myself to unrealistic expectations. While training for my demonstration fight, I regularly went 
home on difficult training days and cried because I did not think I was improving. Demonstration fights are different than sanctioned fights because there is no winner or loser recorded on a fighter's record. They are meant to ease a fighter into the ring with a more controlled fight. It was not until a Capoeira teammate introduced me to self-progress tracking and thought diary exercises that my mindset improved. These tactics reappeared when I began experiencing anxiety and was referred for cognitive behavioural therapy (CBT). This section will explore barriers for women, tools for success, and general resilience strategies, as well as the concept of flow, something that is relevant to both martial arts and gameplay design.

\section{Barriers for Women}

As Melanie Joy McNaughton noted within my Muay Thai subsection, women in athletics are frequently characterized as weak and less competitive. To excel in their sports, women often reject traditional gender roles. Dorcas Susan Butt notes in her work in the psychology field that there are common traits among athletes who have adjusted to careers in their sport including, “dominance, extraversion, enthusiasm, confidence, and resilience" (107). She states that although there are introverted personalities in sport, the environment created by sports emphasizes external rewards and competition (112). Based on communication scholar Melanie Joy McNaughton's assertion that women are traditionally seen as gentle and weak, I believe these "extroverted" traits are conventionally associated with traditional male gender roles as opposed to female gender roles. Kathleen Noble states that women are socialized to fit restrictive gender roles and relinquish their own needs to fulfill the needs of others (415). These rigid gender roles produce other barriers that facing women, such as self-imposed perfectionism, 
which makes gifted women hesitant to take risks. To address this issue, Noble connects the ability to take risks to a Buddhist concept called Beginner's Mind, "a fundamental attitude that enables us to approach each experience with cognitive, emotional, and spiritual flexibility and a willingness to learn" (417). As discussed in the previous section of the literature review, Muay Thai is heavily influenced by Buddhism. While the discourse around Buddhism is varied between cultural contexts, character-building, spirituality, and introspection are all key components. The concept of the Beginner's Mind may be linked to Muay Thai in this way, as opposed to the warrior spirit and militarism. Lastly, socio-economic and cultural considerations come into play as a barrier for women in sport, as family income and family perception of athletic roles for women can influence the range of opportunities available for women to participate in sports (Butt, 123).

\section{Tools for Success for Women}

To overcome the aforementioned barriers, scholars in psychology identify several tools which aid women in achieving success. Kevin Wildenhaus' work describes several mental training tactics that are used in addition to physical training for female athletes. In one case, a psychologist used "visualization, goal setting, and the use of a self-hypnotic technique" to improve an athlete's performance (345). Some of the techniques for mental training that Dorcas Susan Butt describes include positive thinking, competence training, meditation, relaxation, and affective control. Kathleen Noble also claims that the cultivation of resilience is beneficial for women, and describes a study conducted in 1974 by Norman Garmezy where features of resilient children included "better communication skills, less impulsivity, more ability to reflect on their 
life experiences, and a belief in their capacity to exercise a degree of control over their environments" (414). While the research was completed using a sample group of children, the findings are relevant for adults too.

Within this third theme identified in the literature is the idea that a strong support group is a crucial resource for the empowerment women. Butt argues that healthy relationships between parents and their children, coaches and athletes, and support groups and athletes are essential to an athlete's development (175). While pep talks, superstition, and anchoring effects are non-essential, they are seen to be helpful to some athletes (176). However, although a strong social circle is important to cultivate resilience, women are often encouraged to believe they must refuse to sacrifice their own talent for the preservation of relationships (Noble, 419).

\section{Resilience \& Growth Mindset}

While not specifically geared towards women, the work of Diana Brecher and Carol S. Dweck on resilience within the fields of psychology have become pervasive in popular culture. Both Diana Brecher's ThriveRU booklets, used by Ryerson University, and the book Growth Mindset by Carol S. Dweck act as self-empowerment guides to cultivate resilience.

The Student Affairs initiative ThriveRU focuses on teaching skills to cultivate resilience, well-being, and an environment where one can thrive in both academic and personal contexts (ThriveRU). The 5 Factor Model of Resilience, designed by Brecher and based in Positive Psychology, expands into five areas which contribute to resilience. The first is mindfulness or "being present at this very moment," and avoiding thinking about the past or future (Brecher). 
The second is gratitude, which focuses on "noticing good things [that] are happening all around you, and taking it in" (Brecher). The third is optimism, "in which we explain why good things happen to us and why bad things happen to us" (Brecher). Tied in with optimism and focusing on cause is self-compassion, which reduces the tendency to place blame on ourselves, and act supportive and kind to ourselves as we would others (Brecher). Lastly is grit that allows us to stick to goals despite the obstacles we may encounter (Brecher). These five factors will be used as a model for resilience when evaluating the data gathered from the interview.

Similar to grit is growth mindset, a concept developed by Carol S. Dweck. She describes growth mindset as "the belief that your basic qualities are things you can cultivate through your efforts" (Dweck, 7). A person who exhibits growth mindset will frequently reframe a setback, loss, or failure as an opportunity to learn and grow, whereas those with fixed mindsets will consider defined by these experiences (33). The growth mindset blends the factors of optimism and grit to consider these experiences as opportunities to thrive and plan for the future.

These two concepts have clear alignment with aforementioned concepts within Muay Thai and Buddhism. Growth mindset is very similar to the Buddhist concept of Beginner's Mind, as discussed by Noble. Furthermore, the factor of grit within Positive Psychology aligns with the concept of heart in Muay Thai, as both consider how to persevere through adversity.

\section{Concept of Flow}

Much like the concepts of growth mindset and resilience, the concept of flow is something that is integral to psychology in athletics. Within Mihaly Csikszentmihalyi's work, he describes flow as "complete absorption in what one does" (Csikszentmihalyi, 239). The concept of flow draws 
attention to intrinsically motivated activity in which an activity itself is more important than the end product, and highlights the way the person becomes absorbed in the activity (240). Being in flow is dependent on balance - if the challenges are more difficult than the skill level, the person becomes "vigilant then anxious", but if the person is too skilled for the challenge then "one first relaxes then becomes bored" (241). This concept is similar to Brecher's mindfulness aspect of the Five Factor Model of Resilience, which focuses on being present. Additionally, the concept of flow also provides insight into the mechanics of motivation, and what motivation can feel or look like. This concept is particularly important to consider when I begin designing the game because of the balance of making the game challenging, but not so challenging it becomes frustrating.

Whether it is balancing physical and mental training, cultivating self-confidence, or maintaining relationships with one's support group, there are a number of strategies women in athletics can use to ensure success. These strategies are set against a backdrop of barriers, such as the characterization of the women as weak and the quest for perfectionism. These tactics and barriers will be integrated into the codes for my analysis of interviews to answer my first research question pertaining to self-motivation strategies. By going into the community, I will evaluate whether the self-motivation strategies identified in the literature align with the actual practices of women in contemporary Muay Thai. 


\section{Electronic \& Traditional Literature}

While the Muay Thai and Motivation subsections of my literature review are most relevant to my data collection, the Electronic \& Traditional Literature subsection focuses on the knowledge translation component of my project. For the knowledge translation component, I chose to use the hypertext fiction program Twine because it has a history of creating games that build empathy and can be used as a pedagogical tool. For example, games like Zoe Quinn's Depression Quest give players an inside glimpse into what it is like to live with depression. In addition to this, Twine is an open source tool which presents a low barrier to entry for creators like myself who are not experienced in more technical aspects of game design.

My approach to the Electronic \& Traditional Literature subsection is twofold: to capture both my experience with video games and my love of traditional print paperbacks. When I was growing up, it was not unusual to see me engrossed in books or video games. My mother used to say that it was impossible to know when I was home because I was so quiet, always laying in my bed or in the den, nose buried in a book or eyes glued to my Gameboy Advance. I was drawn to narrative, and both of these formats presented compelling stories. I would spend hours reading through the Harry Potter series or playing my way through games like Pokemon, Final Fantasy, or Golden Sun.

One of the goals of this project is to create an interactive digital fiction piece through Twine to depict a "typical" female amateur Muay Thai fighter, which will give non-academic audiences access to my research. It will create a story that can be experienced in the same way I did as a young child. As such, scholarly texts on electronic literature and narrative techniques are 
necessary to inform this research creation project. The electronic literature section of this literature review has three main focuses: hypertext fiction strategies, general narrative strategies, and practical considerations.

\section{Hypertext Fiction Strategies}

As a definition of digital literature, English Literature scholar Sarah Sloane defines digital fictions to "encompass stories that are written on or by computers, read via a computer interface, that are one genre of ... cybertext" (21). Key to digital fiction is hypertext, which is information and graphics displayed on a screen that can be clicked and accessed. As scholar of hypertext fiction within English Literature J. Yellowlees Douglas, notes, digital fiction-especially online games-are set apart from novels and other storytelling forms because of their use of sequence in a way that the reader controls (38). These are interactive media which involve the activity of the reader, and have the following features: interruptibility, in which participants can be active or passive; fine granularity where participants do not have to wait until the end to interact with something; graceful degradation, meaning the participants can continue the action without interruption; limited look ahead so the participant does not know the ending; absence of a default path; and the illusion that there is an infinite database of possibilities (43). Sarah Sloane argues that hypertexts "insist on a faster rate of reading," (119) and therefore aspects of language like long sentences, lengthy paragraphs, many propositions, and specialized vocabulary should be avoided so as not to slow down the reader. While it may appear that the absence of long sentences, lengthy paragraphs, and specialized vocabulary suggests that digital fiction is limited and cannot engage with complex topics or communicate complex messages, it actually serves as 
the most suitable platform for my knowledge translation project. Since knowledge translation is about reaching a non-specialized audience beyond academia, I look forward to implementing these strategies while still communicating complex ideas in my own Twine game. Lastly, Sloane positions hypertext fiction as a new way to critique dominant societal values that are apparent in publishing industries, marketing for these texts, and how society receives these texts (109).

\section{Traditional Fiction Strategies}

While there are important differences between traditional and digital fiction, that latter is still rooted in traditional narrative forms such as books and oral storytelling. Literary scholar Marie-Laure Ryan states that the structure of hypertext fiction builds off of Choose Your Own Adventure books given to children (44). This is consistent with Sarah Sloane's analysis, which suggests that digital fiction is closely related to Choose Your Own Adventure books or Pick-A-Plot stories due to "their discontinuous form, paratactic narrative structure, and vague sense of an ending" (121). Since digital fiction is connected to traditional narrative forms, the use of broader narrative techniques is necessary to the project. J. Yellowlees Douglas insists that central to narratives are connectedness, sequence, and order, which reflect our own structured perception of the world (64). However, leaving gaps in the narrative is also necessary since, as Douglas states, "gaps are precisely what enables us to engage in the act of 'directed creation'... by leaving readers with what Sterne in Tristram Shandy called 'something to imagine"' (67). Important features to the narrative structure include background information, kernels essential to the plot, action sequences, exposition of characters and settings, transitions between sequences, distinct character voices, and the tone (Douglas, 68). 


\section{Considerations for Twine Game}

\section{Content}

In her book What's Your Quest: From Adventure Games to Interactive Books, digital media scholar Anastasia Salter points to the adventure game in which a player follows a viewpoint character from the beginning to the end as valuable model to understand the future of narrative (Salter, 5). She describes several elements in the adventure game which make it ideal for interactive storytelling such as the focus on a character that the player may not identify with; the use of traditional narrative techniques which interweave reading and playing; the genre's fans as storytellers and the focus on the player-creator relationship; and the modern adventure game as a tool for personal storytelling (6-7). I intend to use Salter's model of the adventure game format as it blends the separated hypertext and digital fiction and traditional print fiction platforms together.

Furthermore, I believe the story of Nai Khanom Tom referenced in the Muay Thai suits the features of the quest narrative she describes. While quest and adventure narratives in Western culture tend to revolve around male protagonists, my project focuses on empowering women and so I use the figure of Ya Mo, a Thai heroine who is both a historical figure and a religious figure, as a foil for Nai Khanom Tom (Nilsen, 1599). This is to consider how women have historically also functioned as heroes within the Thai culture. As referred to as Thai Suranari, Ya Mo, Lady Mo, or grandmother Mo, this figure fought Vientiane rebels who opposed Bangkok and the King of Siam with her citizens and army. The key points to this legend are "her courage, her cunning schemes, her clear-sightedness, her leadership and her female charm" along with "her love and 
patriotism for her home city, Khorat" (1600). She is considered "a warrior and a guardian, but also a grandmother and a symbol of kinship and loving kindness" (1601). Throughout the game creation, I will use both Nai Khanom Tom and Ya Mo as hero figures in the quest I create to overlap concepts of feminine and masculine heroship. Ya Mo in particular is able to embody both of these sides, being a symbol of warriorship but also of kinship.

\section{Structure}

As previously mentioned, I will use Twine to create my digital fiction piece. In video game designer and developer, author, and a zine creator Merritt Kopas' collection Video Games for Humans: Twine Authors in Conversation, she describes Twine as a parallel to the Choose Your Own Adventure books previously mentioned (Kopas, 9). Using branching narratives and hypertext, Twine games create interactive web pages meant to be both read and played. One of the appeals of Twine for me as a creator is that it is free and open source software. Twine has become particularly popular among "economically marginalized, nontraditional game designers-i.e. People who are not white men with college-level programming training" because of its user-friendly interface that requires no coding, and instead allows for the construction of a storyboard with logical connecting paths (Kopas, 10).

One model for my game production is the incredibly popular Twine game Depression Quest by Zoe Quinn, a video game developer and programmer, because of its use of the platform to create empathy and teach the audience. As discussed during fellow game designer Toni Pizza's playthrough in Merritt Kopas' collection, the game depicts someone living with depression in a way that "is not meant to be a fun or lighthearted experience" (383). Toni Pizza described the narrator as "self-aware" (385). Throughout the playthrough, many options are 
crossed out such as "shake off your funk and have a good time" because of the reality of the narrator's depression (389). Toni Pizza's playthrough shows the way that Twine can be used for responding or at least acknowledging barriers. In an interview with The New Yorker journalist Simon Parkin, Zoe Quinn noted that video games became her refuge when medication didn't help her depression and her family could not afford therapy. She eventually took a course on video game design, and allowed her to meet her collaborator Lindsey. The pair decided to "communicate their experiences [with depression] through a computer game" in a way that didn't frame mental illness as a metaphor (Parkin). Quinn also noted that the game was "an ideal way to create an experience that builds an understanding between sufferers and non-sufferers" (Parkin). Quinn's approach shows that Twine is a suitable medium to create empathy, which in turn will be used for my own game as I showcase the barriers women face participating in Muay Thai.

Another model for my Twine game is The Temple of No. Whereas Depression Quest is a serious game with heavy subject matter, The Temple of No is a lighthearted fable. Choosing between three possible protagonists_-"a woman, a bloke or a frog" - the user is told a story about an adventurer who is following a map in the jungle. Polygon writer Allegra Frank praised the game for its use of narrative, self-aware jokes, and quick playthrough time, calling it "the most fun 10 minutes you'll have today" (Frank). Steven Messner of Rock, Paper, Shotgun also praised the Twine game for similar aspects for its "fourth wall-breaking," the illustrations by Dominik Johann, and the "silly and short" format (Messner). Most important to this user was the numerous choices available during the playthrough, which prompted him to "[play] Temple of No several times to experience each of the branching choices" (Messner). The Temple of No 
serves as a model for the structural design because of its quick playthrough time of ten minutes and branching narrative, which was widely well received.

Lastly, when discussing hypertext fiction, it is important to acknowledge Michael Joyce's Twelve Blue. As the Electronic Literature Organization notes, Michael Joyce is considered the author of the first hypertext fiction. Twelve Blue was his first web hypertext fiction, published in 1996 (Electronic Literature Organization). The branching narrative which "[forms] patterns of interlocking, multiple, and recurrent surfaces" was one of the first of its kind. While Michael Joyce would have done the HTML coding for each individual page in 1996, today Twine serves as an open source program that codes the story for the user.

Coming from an English Literature and Creative Writing educational background, I believe that the use of classic storytelling forms and features, such as characters, setting, and plot, are integral to the success of new media storytelling. This inference is confirmed by aforementioned texts by Anastasia Salter and J. Yellowlees Douglas. This is why connecting the style of hypertext and digital fiction back to older forms like Choose Your Own Adventure storybooks is important. However, noting the way the text differs from print forms is also critical to ensure the user experience is enjoyable. The use of sequence, variation, and interactivity will be implemented to create a Twine game that is interesting to players. The speed which the user reads is important when creating the text, and informs my writing process which is aimed at producing short and concise fictional texts. The myths of Ya Mo and Nai Khanom Tom will inform the way I craft narrative. Lastly, I will use previous Twine and hypertext fiction such as Depression Quest and Temple of No as models for effective game design for teaching and engaging an audience. 


\section{Data Collection Approach}

\section{Ethnography \& Autoethnography: An Extension of Biography \&}

\section{Autobiography}

For my data collection approach, I conducted an ethnography of female Muay Thai fighters through interviews. My interest in ethnography comes from my passion for biographies and autobiographies. Both biographies and autobiographies are popular in the world of sports and combat arts. For MMA, books by MMA fighters like Ronda Rousey’s My Fight/Your Fight and Sam Sheridan's A Fighter's Heart are bestsellers, and offer a glimpse into a specific community the way ethnographies do. Ethnography differs from biography because it is often more critical, nuanced, and rigorous in the analysis of its subjects. Based on Alan Bryman and Edward Bell's textbook Social Research Methods, I assumed the role of complete participant in this ethnography. The drawback to this approach is that I would have more involvement and the risk of over-identification (186). Choosing ethnography as a data collection approach was heavily influenced by Loic Wacquant's Body \& Soul: Notebooks of An Apprentice Boxer in which the French sociologist trained boxing in a black neighbourhood in Chicago's South Side, and Erica Rand's Red Nails, Black Skates: Gender, Cash and Pleasure On and Off the Ice which tracks Erica Rand's recounts her experience as a queer femme returning to figure skating. Whereas Wacquant had never boxed or lived in Chicago and inserted himself as an outsider, Rand had previously skated as a child. 
My project is similar to Rand's in that I belong to the culture that I am studying. I have been training in Muay Thai since 2014 and participated in one demonstration match in August 2016. While demonstration matches do not have a win or lose aspect as sanctioned fights do, they still require the same intense preparation and can be equally as dangerous. In my experience, Muay Thai is a community-based activity, especially for fighters. When an athlete is preparing for a fight, coaches and teammates alike typically come to support them. While I was training for my demonstration match, many of the female athletes gave me advice and comfort on my most physically and emotionally difficult days. Due to my place in the ethnography, my contacts were very comfortable speaking to me confidentially about their experiences training Muay Thai and their opinions on the representation of women in the sport.

To ensure voluntary participation despite our existing relationship, I reiterated multiple times throughout the recruitment and interview process that participation in the interview was voluntary, it would not alter our relationship, and participants were able to withdraw at any time.

\section{Semi-Structured Interviews: A Journalism Staple}

My desire to use semi-structured interviews does not stem from academia. Instead, the models for my semi-structured interviews are from journalists. In the collection Telling True Stories released by the Nieman Foundation at Harvard University, Isabel Wilkerson describes interviewing as "accelerated intimacy" (30). In her essay, she describes interviews as "guided conversations" which is actually as much about building a relationship with the subject as it is about getting the quotation you need for the story (31). The most important part about letting the subject guide the conversation is to allow them to "feel comfortable enough to reveal something 
very candid or deep" (32) and feel "free to say almost anything" (33). Semi-structured interviews allow for this subject-guided conversation because the questions are not rigid and specific. Within this same collection, S. Mitra Kalita notes the difficulty of reporting on a culture that you are a part of. When reporting on your own culture, it is necessary to include "background, context, and complexities" for the general audience (49). While my decision to use semi-structured interviews did not come from academia, semi-structured interviews have long been used by academic researchers. Alan Bryman and Edward Bell describe the method as "[having] a list of questions... but the interviewee still has a great deal of leeway in deciding how to reply" (199). Similar to the accelerated intimacy that Wilkerson describes, Bryman and Bell claim unstructured and semi-structured interviews are "designed to bring out how the interviewees themselves interpret and make sense of issues and events" (200).

Using a qualitative approach, I interviewed 10 female Muay Thai athletes in the GTA and surrounding areas. These women had to be 18 years or older and have competed in one or more Muay Thai fights within their lifetime. Recruitment was done through personal contacts and warm referrals since I have trained in the Muay Thai community. These interviews were semi-structured and spanned 30 to 45 minutes.

Questions were grouped into 2 types. The first set focused on the participants' backgrounds in Muay Thai, the motivational factors behind the athletes' decision to fight, and the specific techniques they use to stay motivated. This part of the interview included questions such as the following: What techniques do your coaches use to motivate you? Which do you find effective and which do you find ineffective? What made you want to fight in Muay Thai at a competitive level? The second set of questions was designed to generate responses that will 
directly influence the game design. I asked participants how they currently see women represented in video games and martial arts shows like the UFC, and how they would want to be represented. An example of this type of question was the following: How do you see women represented in sports, particularly in combat sports productions like the UFC or Invicta?

These questions drew directly from my literature review in the Motivation and Muay Thai sections. When asking about the techniques used to motivate and self-motivate these athletes, I expected to hear answers that appeared in my scholarly sources such as meditation and visualization. However, I framed questions in a general way to avoid imposing my assumptions onto these athletes. The questions also engaged with the theme of the portrayal as weak which appeared in the literature review. Lastly, these questions were structured to answer my overarching research questions. For example, the first sample question mentioned above sought to verify whether the techniques identified in the literature review are still used today by women in the Muay Thai context. Likewise, the third sample question engages in the second research question, which is focused on the accurate representation of women to build empathy and depict their experiences. A full list of questions asked is included as Appendix A.

This research plan was approved by the Ryerson Ethics Board as of February 6, 2018. Recruitment began February 6, and continued to occur through snowball sampling when participants recommend other female Muay Thai fighters to me. Interviews occurred between February 6, 2018 and May 1, 2018. The suggested location for interviews was at Ryerson University or at an office in their Muay Thai gym. Alternative formats were also offered including Facebook video/audio call, Skype, Google Hangouts, and traditional phone calls. Many of the interviews took place in coffee shops or restaurants at the participants' request. 
Secondary demographic information was collected on age, education level, gender, and ethnic and racial identity.

\section{Method of Analysis}

\section{Autoethnography}

Since I belong to the culture that I am studying, it seems natural to use autoethnography to consider the ways I have experienced Muay Thai in ways that are similar or different to my participants. The form of autoethnography I have chosen to integrate could fit a number of forms. Reflexive autoethnography "documents ways a researcher changes as a result of doing fieldwork" and shows my own experience alongside the women I have researched (Ellis, 5). Similarly, this could be considered a community ethnography because it uses personal experience "to illustrate how a community manifests particular social/cultural issues" and focus on making opportunities for community-building and social intervention (Ellis, 6). Autoethnography has been criticized for being too focused on the personal experiences of the researcher. However, I believe that my experiences as a fellow martial artist allow me to better analyze the data. Although I have regularly peppered anecdotes throughout this paper, the reflexive autoethnography is a more critical approach that puts my experiences in conversation with other female Muay Thai fighters. As discussed above, I use Erica Rand as a model for for autoethnography as well from her book Red Nails, Black Skates: Gender, Cash, and Pleasure On and Off the Ice. 


\section{Thematic Grouping}

After recording the interviews, I completed targeted transcription. Targeted transcription was chosen over full transcription because of my thumb injury, which prevents me from typing for long periods of time. Once the targeted transcription was complete, I grouped them thematically to find trends. I chose thematic grouping based on chapter 16: Content Analysis within Social Research Methods by Alan Bryman and Edward Bell. I created a coding manual based on the literature review, focusing on subjects and themes which emerged within the literature such as internal motivation strategies and external barriers. Through a process of grouping quotes thematically in an Excel spreadsheet, I found information that pertained to either motivation strategies or best practices for fair representation in the game design. The themes were informed by the trends and key terms found in my literature review, but I allowed for the addition of themes that were not found in the literature. For example, while I intended to only create one subtopic for specific game suggestions, I soon found that important emergent issues such as body image or weight cuts. Internal and external communication were emergent themes that occurred during data collection and analysis rather than within the literature review. It was imperative to include these emergent themes as another subtopic to later be integrated as plot points during the game design.

Much like the data collection approach, the analysis sought to engage with my research questions. The findings are structured in two parts: the analysis of motivation strategies in Muay Thai and the considerations for my game creation. For the safety of the participants, the Excel data $\log$ will not be included as an appendix. This is to avoid the possibility for someone be 
identified based on their quote. My results are also not explicitly quantified for the same reason. Instead of using specific numbers, I use words like many, all, or one when referring to participants to avoid singling anyone out. I have also chosen to avoid quantifying to avoid dehumanizing my participants into numbers. John W. Murphy and John T. Pardeck discusses the dehumanization of people through technology in a clinical practice where intake was being done by computers rather than staff in his article "Dehumanization, Computers and Clinical Practice." In the article, he urges practitioners to examine "the conceptual "underside" of computers" and be aware of "the early stages of the diagnostic process, such as in-take interview, can be profoundly distorted by the computer micro-world" (114). Similarly, in the non-academic sphere of Harper's Magazine, Mark Slouka argues in his article "Dehumanized: When math and science rule the school" that presently, "orthodoxy is economic" (33). In turn, every action in research and education is measured in economic language for profitable achievements with phrases like "the return on modest investment in writing is manifold" (34). In my own experience, statistics such as census data have often felt impersonal. This is because the individual experience gets added together to produce a mosaic of the community being studied. The process of being turned into a statistic has been more difficult for me as a woman of Indo-Guyanese descent because of the lack of options to correctly self-identify as a woman of South Asian, Caribbean, and South American descent. For this reason, I will not be quantifying my participants nor producing graphs or data visualizations to represent their experiences. 


\section{Findings}

This section is divided into three sections: external communication, internal communication, and considerations for game design. In the context of my study, external communication refers to how both media, social media, coaches, and others communicate with the female fighters in a way that either empowers or disempowers them. Internal communication refers to the way that these fighters communicate with themselves to build their own resilience. Lastly, the considerations for game design consists of suggestions for the Twine game creation from the participants.

\section{External Communication}

As previously stated in the literature review, there were a number of barriers which prevented me from even trying Muay Thai. Scholars Dorcas Susan Butt, Kathleen Noble, and Melanie Joy McNaughton all pointed to the characterization of women as weak or gentle in the literature review, which is something I faced when I started training with the specific opinions of friends and family, and more general societal views on what women should do. The participants shared similar experiences surrounding gender roles. Whether it was through their coaches' approach to training, their own self-imposed perfectionism, or representations of female fighters in the media that they didn't relate to, my interviewees found many forms of external communication to be stifling. 


\section{Barriers}

The participants reported that they experienced a number of different barriers when beginning to train and/or fight. The first was self-imposed high expectations, as discussed above in relation to Noble's work. For example, one participant described feeling imposter syndrome because many of the younger fighters looked to her as a role model. She did not always feel that this was earned. Although she saw herself as one of the hardest working fighters in the gym, her fight record was not as strong as she expected. Another participant stated that she initially did not want to fight because she did not believe it was for her, to which her partner asked, "Why isn't it for you?" She pointed to this self-doubt as learned behaviour, and said that it is easy to think that you do not have a fighter's heart when in fact what you need is encouragement. These types of feelings are exacerbated by the negative response from other fighters in the gym to expressing emotion in the form of tears, which was considered "offensive" or "girly." The use of the word "girly" points to the dominant masculinity within a martial arts gym that was discussed in the literature review by Melanie Joy McNaughton. Many participants claimed that the only acceptable form of emotion within the Muay Thai gym was anger or rage.

Beyond the internal barriers, many participants also noted external barriers in their social circles. The parents of these fighters frequently disapproved of their decisions to fight, but nevertheless supported the fighters in different ways. Even if they did not attend the fights, parents would ask about how it went or cook the fighter's favourite meal for them after the fight. At the time of choosing to fight, many of these women were older and not living at home, which reduced the parents' influence on the fighters' decisions. Lastly, one participant stressed that if 
mental barriers become a frequent problem while fighting, it may point to a larger issue outside the ring, and it could be worth reaching out to mental health professionals.

\section{Coaching Tools}

Within Muay Thai gyms, it is not uncommon to have a combination of coaches. Almost all of the fighters described at one point having an ineffective coach who used an "old school" approach and imposed the same training regimen on everyone. Some of the participants considered these training styles outdated while others saw it as fair in the gym since it encouraged both men and women to work at the same pace. However, none of the participants found a "one-size-fits-all" approach effective for growth and preparation for their fights. The challenge for coaches is that training styles are often historical knowledge that is passed down - the training style is regarded as "the way it was always done." For example, many of the participants stated that coaches would inform the weight cut—-the process of losing weight to be eligible to fight in a weight class - in ways that were not always healthy and effective for them, such as encouraging diet changes or sauna sessions. In terms of emotional training, when one participant was doubting that she would be successful in her fight, her coach told her to ignore the thoughts rather than address them. Although many coaches rightfully told the participants that fighting emotionally can create a hole in their fight game that could be exploited by opponents, participants expressed that suppressing emotion often leads to emotional "meltdowns." Lastly, one participant stated that her coaches only cared about her and other fighters when they were in the spotlight and actively winning. The coaches did not give her or other fighters attention when they were injured or taking time off to heal. When faced with a coach that did not fully support their emotional growth, it was integral for the fighters to develop self-motivation strategies to compensate. 
In contrast to the ineffectiveness of the approaches noted above, participants pointed to a number of positive experiences with coaches. When these female fighters switched from training recreationally to competitively, the coaches were frequently described as the deciding factor. One participant pointed to the gendered dynamic of having a male coach say that she could fight as empowering, as though being invited in to a male-dominated world. All of the participants insisted that they thrived when they had a coach who was invested in their growth and knew them on a personal level. One participant described feeling an obligation of reciprocity because she knew the coach was so invested in her. Many of the participants described the importance of this personalized approach as the cultivation of trust.

The most frequently noted effective coaching technique was constructive criticism. All of the participants pointed to the importance of their coach knowing when they needed encouragement and when they needed "tough love." Tough love—which could be seen as being very hard on the fighter, yelling, and insisting they need to work harder — was most helpful when used on more experienced female fighters and was perceived to be integral to overcoming plateaus. This form of coach-athlete communication reinforces the dominant hegemonic masculinity discussed in the literature review by scholars Peter Vali, Akihiko Hirose, Kay-Kei-ho Pi, and Melanie Joy McNaughton. In contrast, tough love frequently fell flat with more inexperienced fighters because they did not feel they had enough self-confidence in their abilities yet. Some fighters, including one more experienced fighter, described the tough love tactic as anxiety-inducing, to the point where they were afraid to train. Some of these fighters felt safe to discuss this with their coaches. Others did not. One of the participants described the need for better emotional training, and said that the coach she resonated with the most was willing to 
have a conversation with her on how her mental and emotional health were and how this was affecting her training. All of the fighters described a need for balancing encouragement and tough love, with the need for some recognition and reassurance at times.

A participant who had trained both in Thailand and in North America explained the difference between these types of coaches. In Thailand, the main motivating factor to train Muay Thai is to earn income. She claimed that since these fighters are quite literally fighting to eat, they do not have room for emotions such as worry, anxiety, or doubt, as well as anger, which could create holes in their game. Instead, the only acceptable concept of emotion is the previously mentioned Jai Dee or heart, which is a form of resilience or perseverance. The participant described this in terms of the socio-economic difference, or difference in privilege, between Thais and North Americans who train Muay Thai.

\section{Representation and Appearance}

\section{Representation in Muay Thai and Combat Arts}

Overall, my participants believed that all athletes in general were not treated or represented with enough respect. Most of the focus was on fight promotions because many of my participants did not play video games. Those who had experience with video games described the portrayal of women as oversexualized and exaggerated. However, they did describe the UFC games as "true to life."

Many of my participants believed that athletes were only valued for their hardware such as medals in the Olympics. They described the pervasive image of martial arts as "the tough man mentality" that was about animosity and ego, whereas Muay Thai in their view was about love 
and respect. One of the participants stated that there should be a line drawn between fight entertainment and martial arts. She considered MMA as complete destruction of the art. Another participant stated a similar point, insisting Muay Thai was beautiful because of its dance, music, culture, and respect aspects, and that UFC was responsible for the erasure of these elements. This aligns with scholars Melanie Joy McNaughton and Peter Vali, who claim that the appropriation of Muay Thai in MMA and the Western media industry decontextualizes the art form.

Representation of women in martial arts was also described negatively. Most of the participants stated that women were underrepresented on fight cards in both MMA and Muay Thai, and in sports more broadly. They stated that such images represent women according to a conventional Western ideal a certain way — white, curvy, slim, with long hair — and those that did not fit this mould were not as celebrated. This corresponds with a patriarchal, colonial, heteronormative ideal of femininity. One participant raised concerns about the lack of racial and ethnic diversity of female fighters in the UFC. One participant also noted that women are forced into emotional moulds as well, giving the example of how quickly the public questioned the emotional merit of Ronda Rousey when she admitted to feeling suicidal after her big loss against Holly Holm after a lengthy winning streak.

Despite participants' dissatisfaction with media portrayals of women in martial arts, many of the participants described female fighters as more exciting to watch than male fighters because they perceived the former to be more aggressive, active, and technical. They did not feel the marketing of these women reflected their skills and instead focused on oversexualizing, merchandizing, and packaging these women for media audiences. The participants were also critical of what they perceived to be disproportionate opportunities given to fighters who are 
more conventionally attractive like Paige Van Zant and Gina Carano who they consider good fighters but not as skilled as others in their bracket. They noted this was very different than the exposure or opportunities given to women who are not conventionally attractive like Cris Cyborg or not hetereosexual like Amanda Nunes. One participant raised concern over Joe Rogan, who is a well loved sports announcer for MMA, and his ignorant remark describing Cris Cyborg as a man.

Participants also commented on the way female fights are marketed as "juicier" or with more insulting exchanges, and there tends to be a strong focus in MMA entertainment on the way female fighters "steal" the show with words and "catfights." A few of the participants described a shift in the recent years with fighters like Rose Namajunas or Valentina Schevenko who talk more positively and respectfully about other fighters. Brands frequently endorsed the more attractive fighters, but some participants said this was similar to actors where appearance matters. However, one participant was critical of the way Ronda Rousey had been featured on Ring Magazine because her boxing skills were not adequate. Participants provided mixed feedback on promotional videos. While some believed that the outfits were lower cut and shorter than necessary, others suggested that these videos were accurate depictions of how female fighters trained.

Most of my participants did not identify with the fighters who were slim, curvy, white, and had long straight hair. They were uncomfortable with fighters taking glamour shots and being oversexualized at press conferences. Some did claim that female fighters were given some choice to be authentic at press conferences, and said many "tomboy" fighters showed up with no makeup. A few participants claimed that Thai fight promotions were similar in their approach, 
and many women have to wear thick, Hollywood-style makeup for promotions like Muay Thai Angels. One participant described a specific trend of oversexualization in which the female fighters who won would take a photograph topless with the belt across her chest. Some of the participants were optimistic and suggested this type of oversexualization is changing.

In my second research question, I asked: Do media images, social media discourse, and communication among fighters and coaches in the Muay Thai gyms support or create barriers for female fighters in the sport? It is clear from the responses from these women that the media images surrounding fight culture do not support them nor reflect them accurately, and instead serve as a barrier. This is in line with Peter Vali's description of Western MMA emphasizing violence, hyper-masculinity, and winning over other benefits such as character-building and philosophical introspection.

\section{Results of Oversexualization of Women}

Many of the women expressed concern over the oversexualization of women in the sport because of the way it has trickled down into social media. One participant worried about how social media affected young female fighters, and gave an example of one female teenage fighter she saw on Instagram who was beginning to post images that were closer to that realm. The participant believed that young women may be tempted to post images like this because of the attention it could warrant, but worried about how that would affect them personally. Another participant was frustrated with the rise of "Instagram models" with no fight experience who would put on wraps and take "sexy" training images for their account, despite not training regularly or rigorously. She was upset about this because her gym, a non-specialized gym that 
housed a recreational Muay Thai program, would often use these women in promotional videos instead of her teammates who were actually skilled fighters. She considered both of these as instances of social media being used for instant gratification that did not acknowledge the amount of time and work that goes into training Muay Thai.

Some participants believed this oversexualization of women in Pro MMA fights also appears in the amateur Muay Thai community as well. There is a certain level of respect in the amateur level of Muay Thai because the community is made up of fighters. However, one participant noted that you will hear the stray comment like "oh she's hot." In one case, the participant had a friend tell her "that girl is too pretty to fight," which she found personally insulting as well. Participants noticed that these comments were frequently made towards out-of-town fighters who were not part of the immediate Muay Thai community in Ontario. Participants noted that like major brands in the UFC, smaller local brands of Muay Thai gear frequently endorsed more conventionally attractive fighters to advertise their goods. However, they believed that these fighters were also extremely skilled. Lastly, there was concern raised about how women are treated in the gym as well. One participant described a time where women were sparring quite hard in preparation for a fight, and the male fighters were laughing as though it was entertaining and not serious. Many of the fighters did not believe the behaviours of their male training partners were intentionally hurtful, but also did not feel they had the agency to reprimand them for what they said. In conclusion, most participants felt that media images and their influence in Muay Thai contributed to the barriers or exacerbated these barriers that women face in the sport. Furthermore, some traditional coaching styles and unsupportive social circles contributed to these barriers to a lesser extent. 


\section{Internal Communication}

The second category of themes which emerged in my findings was internal communication. In this context, internal communication refers to strategies in which participants communicate with themselves. This concept focuses attention on how each fighter communicated with herself to ensure she felt empowered. There were three major sub-themes which emerged: discipline and organization; resilience and growth mindset; and purpose.

\section{Discipline \& Organization}

While scrolling through Instagram, one of my participants came across a post by a Swedish fighter. As my participant recounted, the post said, "motivation is bullshit because if you're not motivated, you'll stop. What you really have to focus on is building habits." My participant described this as a post that resonated with her. Similarly, the majority of my participants placed heavy emphasis on having good habits and organization strategies. Journals were used to track a variety of aspects of the fight preparation including strength and conditioning training, practice on the heavy bags, and the weight cut. Journaling helped create a mindset of self-awareness and self-reflection. One participant who had experience with Cognitive Behavioural Therapy (CBT) treatment found this especially useful because of the overlap of journaling and mindfulness practices between CBT and Muay Thai, which resonated with my own experience.. Beyond journaling was goal setting. One participant described her desire to beat her record every day, whether it was in running or conditioning; another pointed to the importance of including achievable goals for every time she trains and having a plan every time she goes into the gym. This self-awareness was also reflected in other ways. For example, one participant personally 
chose to run instead of skip for the maintenance of her knee health, and many of the participants watched their sparring sessions to self-identify areas for improvement. Lastly, the participants stated the necessity to build in rest days into their schedules, whether that was for a pedicure, massage, or simply taking an epsom salt bath.

\section{Resilience \& Growth Mindset}

The women in my study exhibited growth mindsets (Dweck), although they did not identify their actions using that term. They cultivated this mindset by staying positive but also striving to be realistic. This included using self-affirmations to build self-confidence. One participant wrote encouraging messages on her sticky notes and placed them in her notebook, her car, and her agenda. Another read a mantra every morning and every night. In one case, the coach taught the

participant to reframe negative thoughts in her mind - instead of saying to herself, "I got hit," she was encouraged to say, "I will block the next kick." This reframed negative instances as opportunities for learning.

\section{Purpose}

While purpose is often grouped together with goal-setting, the concept of purpose for these women differed. Goal setting to my interviewees was something that could be measured and tracked. In contrast, purpose was a constant overarching theme that they would come back to as a touchpoint to remind them why they started or why they fight. This empowered the fighters by reasserting their agency as well as by creating a narrative structure. All of my participants agreed that it was important to find purpose and understand why you are fighting. Many of the participants did this by setting intentions every day and sticking to them, calling back to the 
importance of organization. Many of them pointed to the importance of reading, and one gym had five books on warriorship which were used to give everyone a similar foundation on fight spirit and purpose. Another way the participants did this was by looking at role models and their purposes. This included watching interviews or following the social media of their favourite fighters such as Tiffany Van Soest, Matt Embree, or Robin Van Roosman among others. In some cases, the best role models were not high profile fighters, but peers in the gym. Many of the participants noted at least one female role model in their gym who they turned to for advice.

Some specific examples of purpose for these participants included enjoyment of playing the game, comparable to chess; the idea of constant growth; attraction to the culture and artistry; pride; recognition among peers and self-satisfaction; and the ability to live intensely, using Muay Thai as a form of self-expression. Interestingly, these examples of purpose for fighting did not align with the participants accounts of their initial reasons for trying Muay Thai. Initial motivating factors to try Muay Thai included cultivating platonic, romantic, or familial relationships; losing weight and being in shape; the desire to do something characterized as 'hard'; an emotional outlet to get over a romantic relationship; wanting to try something new; interest based on media representation of female combat artists such as in Kill Bill, Elektra, and Girlfight.

Interviewees also reported that there were a number of factors that did not motivate them, including "hardware" such as medals or trophies; fans, fame, and popularity; and doing it for anyone but yourself, such as your coach. 


\section{Motivational Communication Practices}

There were a number of strategies that did not fall into these major categories but contributed to motivation including: meditation and mindfulness; visualization; taking mental and physical breaks for self-care; training at other bootcamps to avoid stagnancy; and avoiding social media. Some participants have accessed mental health services including specialized professionals for athletes and non-specialized professionals. Lastly, many of the participants stressed the importance of remembering that fighting is only one part of their life, and each fight is only a small part of their fight record.

\section{Considerations for Game Creations}

As previously mentioned, the end goal of the project is to create a Twine game as a knowledge translation product. To ensure fair and ethical representation of my subjects and their experiences in the game, I asked for suggestions during the interviews.

\section{Audio-Visual Considerations}

There were a number of specific suggestions for the game, primarily based on appearance, sound, and plot points. For appearance, the participants asked for a reversal of the oversexualization depicted in the representation of female fighters in fight promotions like the UFC. They asked for women who were lean, strong, and fit and suggested Tiffany Van Soest as a model. Many participants said that it was fine to have a variety of body types which included being curvy, tall, skinny, or having long blond hair, but suggested having some sort of feature that pushed against them being a stereotype. One suggestion to accomplish this was allowing 
them to wear board shorts or baggy shorts, or putting a muscular body like Cris Cyborg's into the spandex shorts. They insisted that they did not want to see the characters scantily clad. One participant requested an option to build an avatar that would allow for choice of skin colour and bodybuilding features.

There was only one request related to sound. One participant requested that the overly-exaggerated sighs that are often integrated in video games be avoided. She also requested to have realistic punch and kicking noises.

\section{Storyline Considerations}

There were many requests on plot points. The most pervasive of these was acknowledging that there is a life outside of the gym and fighting. The participants wanted an acknowledgement of important decisions or sacrifices that come with fighting, especially sacrificing time with family and friends. One participant suggested an all female roster that shows pathways from different countries with a range of types of background rather than the sensationalized trauma that is common in video game plot lines

The participants also requested many plot points related to the body including the difficulty of weight cut for women; body image issues such as thinking they are always too big; the menstrual cycle including cutting weight on their period, periods disappearing, and fighting on the day of their periods with body sensitivity and cramps; needing services like physiotherapy and nutritionists but not always being able to afford it; and concussions and injury. There was a heavy emphasis placed on the danger of concussions and injury and the tendency of many coaches to minimize these risks to fighters. 
There were also requests for discussion of emotional and interpersonal plot points including opportunities for self-reflection; acknowledging frustration; training as as hard or harder than men while knowing that they won't get the same attention or understanding; distinguishing emotional vulnerability from weakness; difficulty with women in the gym including unhealthy competition and chattiness which involved gossip and served as a distraction from training; and the lack of opportunity for women to fight and teach in Muay Thai.

\section{Discussion}

There were several topics that emerged from the findings that will be discussed further to showcase suggestions. I have grouped them to match the format of the findings: external communication; internal communications; and the game creation.

\section{External Communication}

Both the coaches and the media representation of female fighters frequently disempowered my interviewees. The findings suggest that female fighters responded best to coaches who understood emotional motivation strategies; were aware of mental health education, including body image; cultivated a relationship with the fighter; consulted with the female fighter on her training, prompting self-reflection; and acknowledged the differences that women faced when cutting weight.

Regarding the representation of female fighters in combat arts, many of the women problematized the way media images of female fighters conform to conventional beauty ideals. 
Some of the ways these representations could be more inclusive include allowing women to dress in a way that feels authentic to the subject (and not exclusively in tight dresses and/or bikinis); marketing all women evenly; showcasing women for their skills rather than their looks; and avoiding focus on "catfights" and instead covering fighters who are considered to be positive and respectful like Rose Namajunas or Valentina Schevenko.

\section{Internal Communication}

The findings for internal communication were in line with the Motivation subsection of literature review, and also included other strategies. Many tools mentioned in the Motivation subsection such as visualization and meditation were used. Furthermore, the concepts of growth mindset and resilience emerged in the interviews without being named as such by the participants. Lastly, a set of tools emerged unexpectedly in the accounts of many of the interviewees who emphasized discipline, organization, and developing an overarching purpose.

These findings suggest that the successful internal communication for my participants exists in three parts. First, all participants had some sort of guiding purpose to reference for motivation. Second, developing good organizational habits and setting achievable, measurable goals led to satisfaction and further motivation. Lastly, growth mindset and resilience ensured that these female fighters saw emergent challenges as opportunities to grow rather than as insurmountable obstacles. 


\section{Game Creation}

As noted, I will be producing a Twine game as the knowledge translation component of this project. I intend to use as many of the participants' suggestions as possible for my game. In regards to the appearance, I will avoid the oversexualization of the female fighter serving as the protagonist both in descriptive text and in any accompanying graphics. While not all plot points can be incorporated because the game will ideally be 15 minutes or less, I will be incorporating the following suggestions: acknowledging a life outside of the gym; depicting some complexity related to weight and/or body image; addressing the risk of injury; developing scenes where the protagonist encounters emotional difficulty such as frustration or stress; and providing the opportunity for the protagonist to self-reflect.

There are a number of suggestions that will not be used because of the structure of my hypertext fiction. The game will not be voiced over or have sound effects, so I will not be incorporating suggestions related to those areas. As the game will follow a single protagonist, I will not be using the suggestion to create an all female roster. However, an all female roster may be a project that I pursue in the future.

\section{Conclusion}

Due to the limited scope of the major research paper, a comprehensive literature review on gender and sports and other areas related to my MRP could not be conducted. However, in the process of conducting my literature review, I identified other areas of literature which would 
valuably contribute to this or similar projects include the study of self-help books and the production of meaning within oneself; external communication in the form of persuasion, negotiation, and conflict resolution; cybernetics and other subsystems that communicate within one's self; Eastern philosophy pertaining to Buddhism and mindfulness. Furthermore, the sources I used on Muay Thai, Thailand, and Buddhism were frequently written by researchers who were outside the culture. The integration of Thai and other East Asian scholars would greatly improve the literature review and theoretical framework of similar projects in this area of study in the future. Regarding interviews and the selection of participants, it would be valuable in future projects to incorporate more diverse bodies and identities of women and non-binary people as well as incorporate Crenshaw's concept of intersectionality. Alternatively, the research could be duplicated with male Muay Thai fighters to compare and contrast the types of effective motivational strategies.

For me, the strategies I learned in martial arts contributed to my success in overcoming my anxiety attacks. When I conducted interviews with my participants, it was like getting the opportunity to interview my heroes. The accounts of all of my participated demonstrated their resilience, inner strength, and sense of purpose. With the creation of the Fight Like a Girl Twine game as the knowledge translation component of this project, I hope that I make their knowledge and expertise in self-motivation and self-empowerment more widely accessible to all. 


\section{Bibliography}

Butt, Dorcas Susan. The psychology of sport: the behavior, motivation, personality and performance of athletes. Van Nostrand Reinhold, 1987.

Bryman, Alan and Edward Bell. Social Research Methods. Oxford University Press: 2016.

Crenshaw, Kimberle. "Demarginalizing the Intersection of Race and Sex: A Black Feminist Critique of Antidiscrimination Doctrine, Feminist Theory and Antiracist Politics." University of Chicago Legal Forum, vol. 1989, no. 1, 1989, pp. 139-167.

Csikszentmihalyi, Mihaly. Flow and the Foundations of Positive Psychology. Springer Netherlands: 2014.

Dweck, Carol S. Mindset: The New Psychology of Success. Ballantine Books: 2006.

Douglas, J. Yellowlees. The End of Books-Or Books without End?: Reading interactive narratives. University of Michigan Press, 2000.

Ellis, Carolyn et al. "Autoethnography: An Overview." Forum: Qualitative Social Research, vol. 12, no.1, 2011, pp. 1-15.

Frank, Allegra. "Crows Crows Crows' New Game Is the Most Fun 10 Minutes You'll Have Today." Polygon, Vox Media, Inc, 20 June 2016, www.polygon.com/2016/6/20/11982668/crows-crows-crows-the-temple-of-no-free-game

Kalita, Mitra S. "Reporting on Your Own.” Telling True Stories, edited by Mark Kramer and Wendy Call. Plume: 2007.

Kislenko, Arne. Culture and customs of Thailand. Greenwood Press, 2004. 
Masatsugu, Michael K. "Beyond This World of Transiency and Impermanence: Japanese

Americans, Dharma Bums, and the Making of American Buddhism during the Early Cold War Years.” Pacific History Review, vol. 77 no. 3, 2008. pp. 423-451

McNaughton, Melanie Joy. "Insurrectionary Womanliness: Gender and the (Boxing) Ring.” The Qualitative Report, vol. 17, no. 33, 2012, pp. 1-13.

Murphy, John W and John T. Pardeck. "Dehumanization, Computers and Clinical Practice." Journal of Social Behavior and Personality, vol. 3, no. 1, 1987, pp. 107-116.

"Nai Khanom Tom - Muaythai Legends." World Muaythai Council, World Muaythai Council, 11

Feb. 2014, www.wmcmuaythai.org/nai-khanomtom.

Nilsen, Marte. "The Spirit of a Heroine: Ya Mo—-Spirit Reverence, Patriotism and Thai Buddhism.” Modern Asian Studies, vol. 45 no. 6, 2011, pp. 1599-1625.

Noble, Kathleen D. "Resilience, Resistance, and Responsibility: Resolving the Dilemma of the Gifted Woman." Remarkable women: perspectives on female talent development, edited by K. Arnold, K. D. Noble, \& R. F. Subotnik, Hampton Press, 1996, pp. 413-423. Parkin, Simon. “Zoe Quinn's Depression Quest.” The New Yorker, The New Yorker, 9 September 2014, www.newyorker.com/tech/elements/zoe-quinns-depression-quest.

Pizza, Toni. “Depression Quest By Zoe Quinn Played By Toni Pizza.” Video Games for Humans: Twine Authors in Conversation, edited by Merritt Kopas. Instar Books: 2015. Rand, Erica. Red Nails, Black Skates: Gender, Cash, and Pleasure On and Off the Ice. Duke University Press: 2012.

Rousey, Ronda, and Maria Burns. Ortiz. My Fight/Your Fight. Arrow, 2016. 
Ryan, Marie Laure. “The Interactive Onion: Layers of User Participation in Digital Narrative Texts." New narratives: stories and storytelling in the digital age, edited by R. E. Page \& B. Thomas, Bison, 2012, pp. 35-62.

Salter, Anastasia. What Is Your Quest: From Adventure Games to Interactive Books. University of Iowa Press: 2014.

Sheridan, Sam. A Fighter's Heart: One Man's Journey Through the World of Fighting. Grove Press, 2008.

Sloane, Sarah. Digital fictions: storytelling in a material world. Ablex Publishing Corporation, 2000.

Slouka, Mark. "Dehumanized: When math and science rule the school." Harper Magazine, 2009 pp. 32-40.

“ThriveRU.” Ryerson University, Ryerson University, www.ryerson.ca/thriveru/.

Vail, Peter. "Muay Thai: Inventing Tradition for a National Symbol." Journal of Social Issues in Southeast Asia, vol. 29, no. 3, 2014, pp. 111-130.

Wacquant, Loic. Body \& Soul: Notebooks of an Apprentice Boxer. Oxford University Press: 2004.

“What It Means to Have 'Heart' in Muay Thai." Muay Thai PROS, Muay Thai Pros Inc., 28 Oct. 2016, muaythaipros.com/means-heart-muay-thai/.

Wildenhaus, Kevin J. (1996). "The Talented Female Athlete: Issues in the Development of Competitive Excellence." Remarkable women: perspectives on female talent development, edited by K. Arnold, K. D. Noble, \& R. F. Subotnik, Hampton Press, 1996, pp. 335-348. 
Wilkerson, Isabel. "Interviewing: Accelerated Intimacy." Telling True Stories, edited by Mark Kramer and Wendy Call. Plume: 2007. 


\section{Appendix A: Interview Questions}

The interviews conducted will be semi-structured interviews and include the following questions:

\section{Topic: Background/History}

1. How long have you training Muay Thai?

2. How long have you been fighting competitively?

\section{Topic: Motivation Factors}

3. What made you want to try Muay Thai? What made you stay training?

4. What made you want to fight in Muay Thai at a competitive level?

5. What techniques do your coaches use to motivate you? Which do you find most effective?

6. What techniques do you use to motivate yourself when you train?

7. What techniques do you use to motivate yourself when you fight (e.g. when you're in the ring)?

\section{Topic: Representation of Women in Combat Arts in the Media}

8. Do you play games or are you familiar with games?

i. How do you see women in games represented? 
9. How do you see women represented in sports, particularly in the UFC, Invicta fight series, Bellator?

i. Does this differ or align from the way you see yourself and other women fighters?

10. Do you have any suggestions for the creation of my own game? How would you want a woman in Muay Thai to be represented? 